\title{
Evaluation of the impact of the horizontal sampling density on the wavelet analysis process
}

\author{
WŁODZIMIERZ MAKIEŁA \\ DAMIAN GOGOLEWSKI *
}

Dr hab. inż. Włodzimierz Makieła, prof. PŚk, wmakiela@tu.kielce.pl, https://orcid.org/0000-0002-5100-6184 - Politechnika Świętokrzyska, Kielce, Polska

Dr inż. Damian Gogolewski, dgogolewski@tu.kielce.pl, https://orcid.org/0000-0003-2653-2980 - Politechnika Świętokrzyska, Kielce, Polska

The paper assesses the impact of horizontal sampling density and level of wavelet decomposition in the aspect of applying mother wavelet to divide components of surface texture. Measurements of surface profiles were made using a contact profilometer applying a specific sample density. Two types of surfaces were prepared: using additive technology and grinding. KEYWORDS: wavelet analysis, filtration, surface roughness, horizontal sampling density

\section{Introduction}

Quality control of geometric structure of the surface of machine parts is an inherent step of every manufacturing process. The development of numerical methods and computer techniques resulted in the use of increasingly complex tools for process diagnostics, enabling the acquisition of relevant information about the tested signal - even in complex models whose analysis - requires high computing power. Classic methods of analyzing the measurement signals are increasingly being replaced by new data processing algorithms. An example is the wavelet transform developed at the turn of the 20th and 21st centuries, which many researchers have recently started using to analyze signals of the surface texture [1-7].

Jiang and Blunt [1] used complex wavelets to detect small but significant surface features. In [2], the authors used wavelet transform to analyze free form surfaces, Chen et al. [3] - for the analysis of the fractal dimension and three-dimensional signals of the surface texture, and Zawada-Tomkiewicz [4] - for the analysis of surface images. Dutta et al. [5] used a two-dimensional wavelet transform to decompose the surface after turning to examine tool wear, Zahouani et al. [6] - for research related to multiscale analysis, and Josso et al. [7] - to characterize the surface and divide it into its components.

A preliminary analysis of the possibilities of using a wavelet transform to separate surface irregularities [8] showed that particular wavelet transformation parameters should be considered, i.e. the type of the mother wavelet, decomposition level and horizontal sampling density. Horizontal sampling density plays an important role in measuring the geometrical structure of the surface - it has a direct impact on the analysis results [9].

\section{Research methodology}

The tests were carried out for two types of surfaces. The surface of C45 steel after circumferential grinding and the surface of 316L steel, obtained as a result of using the SLM (selective laser melting) manufacturing technique, were analyzed.

Using the Form Talysurf PGI 1200 contact profilometer, three surface profiles of samples were measured with a specific density of measuring points. The measurement of each profile was carried out so as to obtain $4,000,8,000$ and 32,000 points on the measuring section. The obtained profiles were analyzed using a Gaussian filter with a specific cut-off length: in the case of ground surface profiles, the $\lambda_{c}=0.8 \mathrm{~mm}$ filter was used, and in the case of a surface profile of a sample made using the additive technique - filter $\lambda_{c}=2.5 \mathrm{~mm}$. The 
roughness profiles obtained as a result of filtration were compared with the profiles resulting from the use of a discrete wavelet transform. Individual primary profiles were analyzed using selected mother wavelets.

The following wavelets were selected on the basis of preliminary tests: db20, coif4, sym6. For each sample at subsequent levels of decomposition, the Pearson correlation coefficient of the profile obtained after wavelet filtration and after filtration using a Gaussian filter was determined. It was assumed that the surface roughness profile resulting from the use of selected wavelet functions will be defined as the sum of the profiles of the details obtained up to a specific level of analysis. In addition, selected parameters of profile roughness were compared: $R a, R q, R t, R s k, R k u, R S m$.

Figures 1 and 2 show examples of surface profiles obtained as a result of measurements with a given horizontal sample density (32,000 measuring points) and after applying Gaussian filtration.

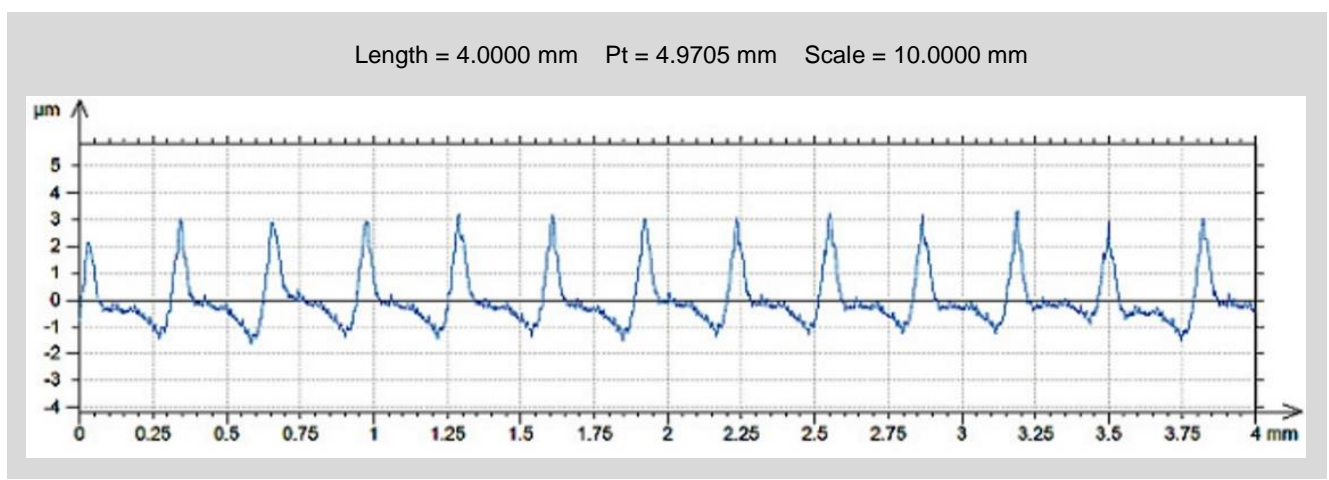

Fig. 1. Surface roughness profile; Gauss filter $\lambda_{c}=0.8 \mathrm{~mm}$

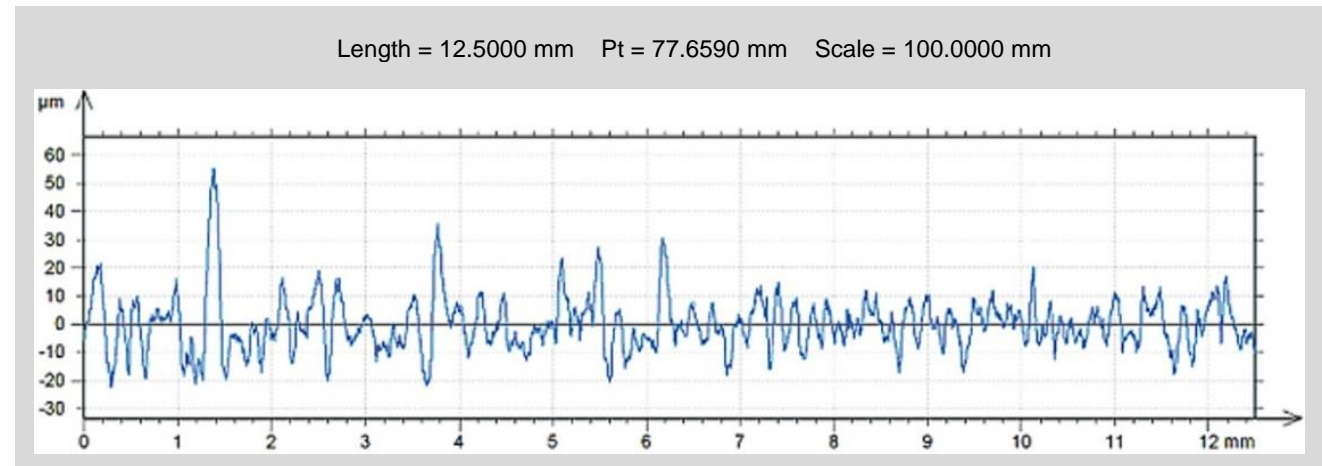

Fig. 2. Profile of surface roughness produced by 3D printing; Gauss filter $\lambda_{c}=2.5 \mathbf{m m}$

\section{Calculation results}

The use of different manufacturing methods determined the variability in the distribution of irregularities in individual surface profiles. Therefore, the impact of horizontal sampling density on the wavelet decomposition process was investigated.

The determined values of Pearson's correlation coefficient for the grinded sample are presented in fig. 3. Similar calculations were carried out for the sample made using the additive technique (fig. 4). The figures show the calculated average correlation parameter values for three surface profiles, with the significance level ( $\alpha=0.05$ was assumed).

The obtained values, referring to the initial stages of the analysis, indicate no relationship between the examined outlines. However, at subsequent levels of decomposition, the coefficient value increases. The profile, which was obtained as a result of summing profiles of details created during the analysis of primary profiles using a one-dimensional discrete wavelet transform, achieves the highest value of the Pearson coefficient with the signal generated after carrying out the Gauss filtration - at the level (depending on the sampling distance): the ninth $(\Delta x=1 \mu \mathrm{m})$, the tenth $(\Delta x=0.5 \mu \mathrm{m})$ or the twelfth $(\Delta x=0.125 \mu \mathrm{m})$ for the grinded sample and the eighth $(\Delta x=3.125 \mu \mathrm{m})$, the ninth $(\Delta x=1.563 \mu \mathrm{m})$ or the eleventh $(\Delta x=0.391 \mu \mathrm{m})$ for the sample produced using additive technology. At the next level of wavelet decomposition, lower values of the Pearson coefficient were obtained. The results shown in fig. 3 and fig. 4 refer to the db20 mother wavelet, however, analogous values were obtained for the other mother wavelets used in the analysis. In tab. I, results of calculations of the level of decomposition were presented, at which the correlation coefficient of the profiles obtained its maxi- 
mum. On this basis, it can be concluded that for the surface of samples with regular distribution of irregularities, the process of wavelet decomposition should be carried out at a greater number of levels than for surfaces with a more random distribution of irregularities.

Results of the analysis in the first decomposition level indicated in tab. I for the db20 mother wavelet, are shown in figs. 5 and 6 . The rough profiles obtained were obtained with a given sampling density $(32,000$ measuring points).

TABLE I. Calculation results: decomposition level

\begin{tabular}{|c|c|c|c|c|c|}
\hline \multicolumn{5}{|c|}{$x[\mu \mathrm{m}]$} \\
\hline 0.125 & 0.5 & 1 & 0.391 & 1.563 & 3.125 \\
\hline \multicolumn{3}{|c|}{ Grinding } & \multicolumn{3}{c|}{ 3D printing } \\
\hline 12 & 10 & 9 & 11 & 9 & 8 \\
\hline
\end{tabular}

a)

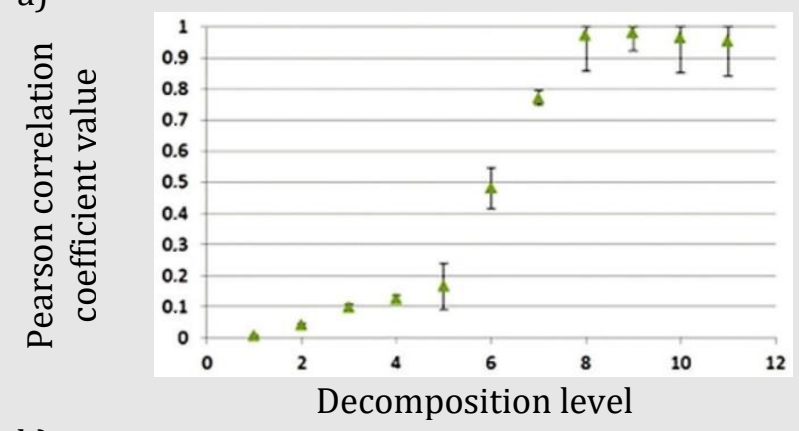

b)
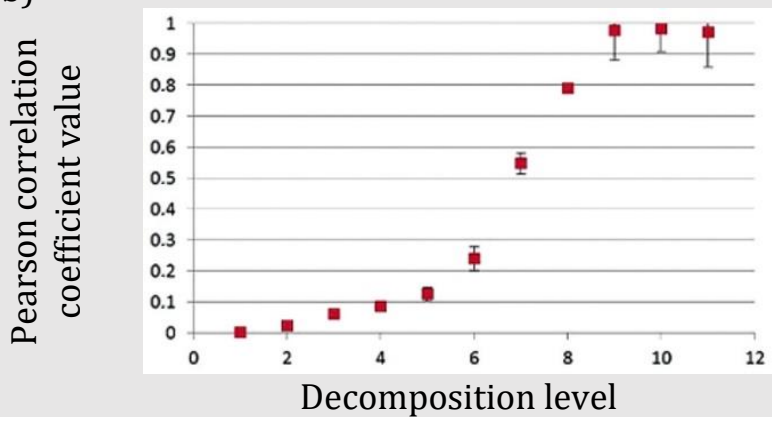

c)

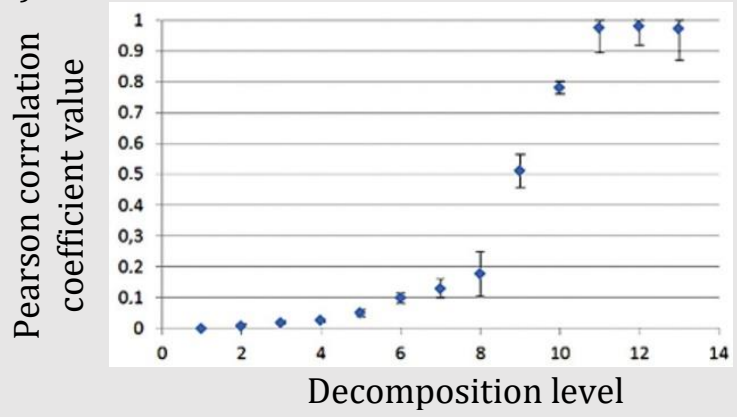

Fig. 3. Correlation coefficient values for a ground sample (db20 mother wavelet) for different sampling intervals:

a) $x=1 \mu \mathrm{m}(4,000$ measuring points),

b) $x=0.5 \mu \mathrm{m}(8,000$ measuring points), c) $x=0.125 \mu \mathrm{m}(32,000$ measuring points $)$

a)

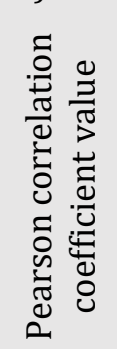

b)
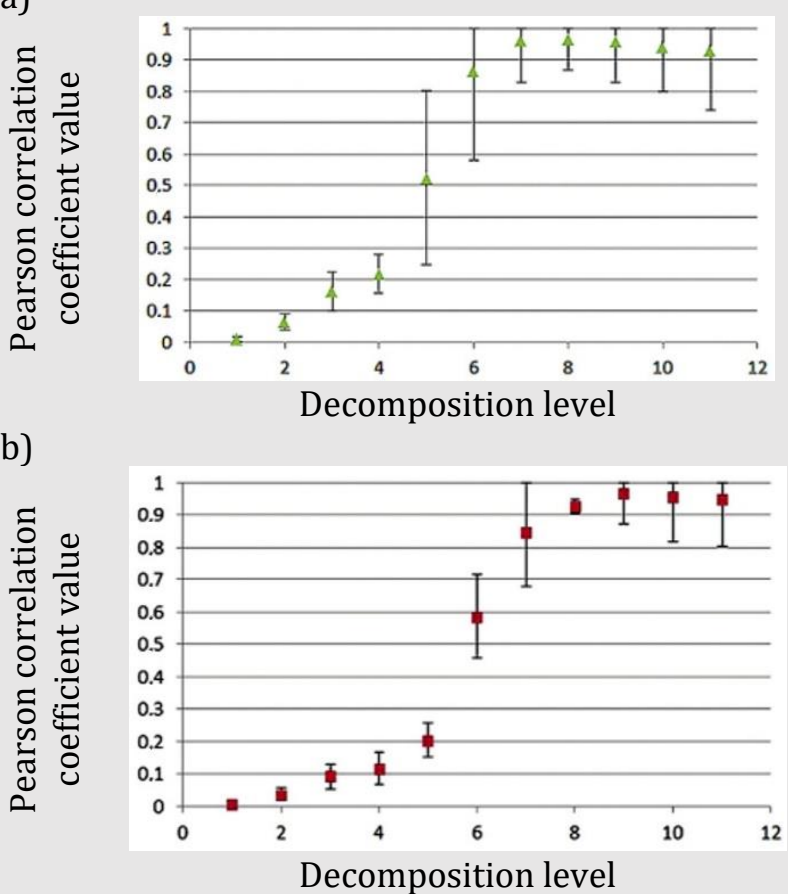

c)

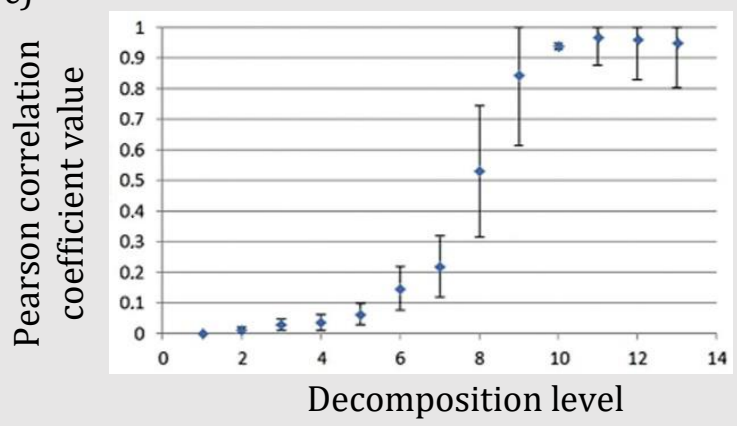

Fig. 4. Correlation coefficient values for a sample made in SLM technology (db20 mother wavelet): a) $x=3.125 \mu \mathrm{m}, \mathrm{b}) x=1.563 \mu \mathrm{m}$, c) $x=0.391 \mu \mathrm{m}$ 


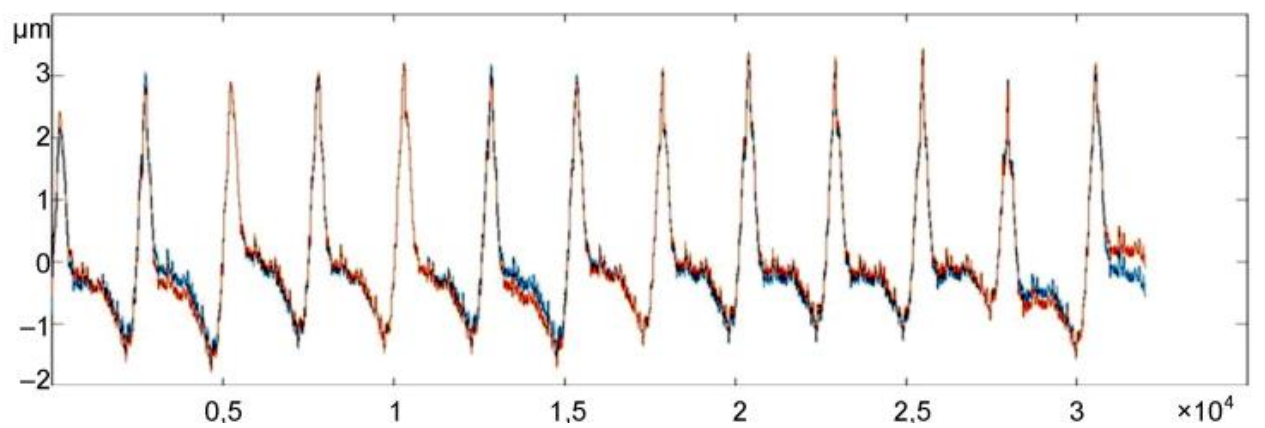

Fig. 5. Surface roughness profile, $\ln =4 \mathrm{~mm}$ (the profile obtained after applying Gauss filtration is marked in blue, and the profile obtained as a result of wavelet analysis in red)

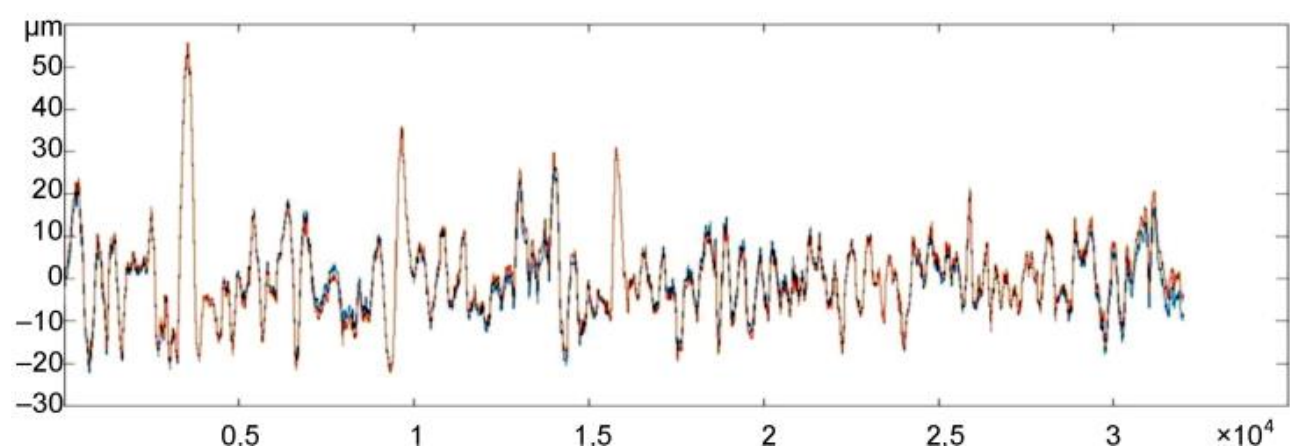

Fig. 6. Surface roughness profile produced by 3D printing, $l n=12.5 \mathrm{~mm}$ (the profile obtained after using Gaussian filtration was marked in blue, and the profile obtained as a result of wavelet analysis in red)

TABLE II. Values of 2D roughness parameters for surface profiles after grinding

\begin{tabular}{|c|c|c|c|c|c|c|}
\hline & $\lambda_{\mathrm{c}}$ & $d w t$ & $\lambda_{\mathrm{c}}$ & $d w t$ & $\lambda_{\mathrm{c}}$ & $d w t$ \\
\hline$x[\mu \mathrm{m}]$ & \multicolumn{2}{|c|}{0.125} & \multicolumn{2}{|c|}{0.5} & \multicolumn{2}{|c|}{1} \\
\hline \multirow{3}{*}{$R a[\mu \mathrm{m}]$} & 0.70 & 0.73 & 0.69 & 0.72 & 0.70 & 0.73 \\
\hline & 0.71 & 0.74 & 0.71 & 0.73 & 0.71 & 0.73 \\
\hline & 0.74 & 0.86 & 0.74 & 0.86 & 0.74 & 0.86 \\
\hline \multirow{3}{*}{$R q[\mu \mathrm{m}]$} & 0.98 & 1.00 & 0.96 & 0.99 & 0.97 & 1.01 \\
\hline & 0.98 & 1.02 & 0.98 & 1.01 & 0.98 & 1.01 \\
\hline & 1.04 & 1.16 & 1.03 & 1.16 & 1.03 & 1.17 \\
\hline \multirow{3}{*}{$R t[\mu \mathrm{m}]$} & 4.97 & 5.21 & 4.94 & 5.25 & 5.00 & 5.45 \\
\hline & 4.80 & 5.14 & 4.80 & 5.18 & 4.78 & 5.16 \\
\hline & 5.86 & 6.99 & 5.86 & 7.01 & 5.81 & 6.94 \\
\hline \multirow{3}{*}{ Rsk } & 1.45 & 1.33 & 1.42 & 1.30 & 1.44 & 1.27 \\
\hline & 1.40 & 1.29 & 1.40 & 1.29 & 1.40 & 1.30 \\
\hline & 1.33 & 0.75 & 1.32 & 0.72 & 1.32 & 0.71 \\
\hline \multirow{3}{*}{$R k u$} & 4.59 & 4.35 & 4.49 & 4.28 & 4.57 & 4.33 \\
\hline & 4.44 & 4.22 & 4.43 & 4.21 & 4.44 & 4.24 \\
\hline & 4.74 & 4.02 & 4.71 & 4.00 & 4.71 & 3.97 \\
\hline \multirow{3}{*}{$R S m[\mathrm{~mm}]$} & 0.23 & 0.21 & 0.24 & 0.20 & 0.23 & 0.21 \\
\hline & 0.17 & 0.19 & 0.19 & 0.25 & 0.22 & 0.25 \\
\hline & 0.17 & 0.27 & 0.17 & 0.29 & 0.24 & 0.27 \\
\hline
\end{tabular}


TABLE III. Values of 2D roughness parameters for surface profiles of elements manufactured using 3D printing

\begin{tabular}{|c|c|c|c|c|c|c|}
\hline & & & & & & \\
\hline & $\lambda_{c}$ & $d w t$ & $\lambda_{\mathrm{c}}$ & $d w t$ & $\lambda_{c}$ & $d w t$ \\
\hline$x[\mu \mathrm{m}]$ & \multicolumn{2}{|c|}{0.391} & \multicolumn{2}{|c|}{1.563} & \multicolumn{2}{|c|}{3.125} \\
\hline \multirow{3}{*}{$R a[\mu \mathrm{m}]$} & 7.07 & 6.75 & 7.20 & 7.36 & 7.16 & 7.31 \\
\hline & 4.52 & 5.23 & 4.43 & 5.11 & 4.42 & 5.09 \\
\hline & 4.11 & 4.85 & 4.11 & 4.34 & 4.08 & 4.79 \\
\hline \multirow{3}{*}{$R q[\mu \mathrm{m}]$} & 9.63 & 9.43 & 9.72 & 9.90 & 9.69 & 9.85 \\
\hline & 5.74 & 6.65 & 5.61 & 6.57 & 5.60 & 6.53 \\
\hline & 5.21 & 6.03 & 5.21 & 5.62 & 5.18 & 5.98 \\
\hline \multirow{3}{*}{$R t[\mu \mathrm{m}]$} & 77.66 & 76.00 & 65.73 & 66.01 & 63.88 & 64.70 \\
\hline & 41.10 & 50.48 & 39.25 & 50.53 & 39.30 & 49.27 \\
\hline & 41.13 & 41.49 & 41.56 & 40.99 & 40.81 & 41.27 \\
\hline \multirow{3}{*}{ Rsk } & 1.18 & 1.25 & 1.08 & 1.05 & 1.09 & 1.07 \\
\hline & 0.17 & 0.40 & 0.22 & 0.52 & 0.23 & 0.54 \\
\hline & 0.00 & 0.20 & 0.02 & 0.23 & 0.03 & 0.19 \\
\hline \multirow{3}{*}{$R k u$} & 7.34 & 7.59 & 5.35 & 5.11 & 5.33 & 5.15 \\
\hline & 3.39 & 3.88 & 3.48 & 4.41 & 3.53 & 4.43 \\
\hline & 3.63 & 3.00 & 3.67 & 3.39 & 3.67 & 3.07 \\
\hline \multirow{3}{*}{$R S m[\mathrm{~mm}]$} & 0.24 & 0.27 & 0.22 & 0.22 & 0.23 & 0.24 \\
\hline & 0.22 & 0.25 & 0.22 & 0.24 & 0.21 & 0.25 \\
\hline & 0.19 & 0.24 & 0.19 & 0.25 & 0.19 & 0.25 \\
\hline
\end{tabular}

TABLE IV. Values of t-Student statistics

\begin{tabular}{|c|c|c|c|c|c|c|}
\cline { 2 - 7 } \multicolumn{1}{c|}{} & \multicolumn{3}{c|}{ Grinding } & \multicolumn{3}{c|}{ 3D Printing } \\
\hline$x[\mu \mathrm{m}]$ & 0,125 & 0,5 & 1 & 0,391 & 1,563 & 3,125 \\
\hline$R a[\mu \mathrm{m}]$ & $-1,949$ & $-1,831$ & $-1,934$ & $-1,097$ & $-2,192$ & $-2,793$ \\
\hline$R q[\mu \mathrm{m}]$ & $-1,927$ & $-1,944$ & $-2,016$ & $-1,433$ & $-2,201$ & $-2,683$ \\
\hline$R t[\mu \mathrm{m}]$ & $-2,025$ & $-2,256$ & $-2,734$ & $-0,793$ & $-0,958$ & $-1,206$ \\
\hline$R s k$ & 1,726 & 1,749 & 1,854 & $-3,452$ & $-1,681$ & $-1,554$ \\
\hline$R k u$ & 2,424 & 2,288 & 2,278 & $-0,11$ & $-0,342$ & $-0,091$ \\
\hline$R s m[\mathrm{~mm}]$ & $-0,897$ & $-0,919$ & $-0,755$ & $-6,143$ & $-1,443$ & $-2,273$ \\
\hline
\end{tabular}

In order for the analysis of the impact of horizontal sampling density on the wavelet decomposition process - in the aspect of its use to separate the primary profile into components of different frequencies - was more complete, the variability of selected 2D roughness parameters was examined. For this purpose, values of parameters were determined both for the profile, profile obtained as a result of Gaussian filtration and for the profile obtained as a result of adding up the coefficients describing the profiles of the details on the level of wavelet decomposition indicated in tab. I. In order to examine whether there are significant differences in their values for the selected parameters, an analysis was performed using the t-Student's test with reference to dependent samples. For the adopted significance level $\alpha=0.05$, the critical value of the test $t_{\alpha}=2.92$ was determined. In tabs. II and III, the determined values of selected 2D roughness parameters obtained for surface profiles after grinding and for surface profiles of elements made using the additive technique are summarized. Table IV presents values of t-Student statistics. 
Based on the data contained in the tables, it can be concluded that at the adopted level of significance for most of the assessed parameters, no significant differences between their values were found. The values of $\mathrm{t}$ Student statistics only in two cases were in the critical area of the test - these are the parameters Rsk and Rsm, determined for the surface profile of the sample made using the additive technique, the measurement of which was carried out with a horizontal sampling interval $x=0.391 \mu \mathrm{m}$.

\section{Summary}

The 2D profiles obtained after measuring two types of samples were analyzed. The tested surface profiles of the sample obtained as a result of circumferential grinding were characterized by regular distribution of surface irregularities, in contrast to the irregularities describing the surface profiles of the sample made using the additive method.

Studies of the impact of horizontal sampling density on the wavelet decomposition process have shown that increasing the sampling density in the analyzed $x$ range results in the need for wavelet analysis to be carried out at more decomposition levels. Doubling the number of measuring points resulted in the need to decompose one level more, while another fourfold increase in the number of measuring points caused the highest correlation coefficient to be noted a further two levels later.

Based on the values collected in tab. I, it can be concluded that in the aspect of using the wavelet transform to separate surface texture components for sample surfaces characterized by regular distribution of surface irregularities, the process of wavelet decomposition should be carried out at a higher number of levels than for sample surfaces for which the distribution of irregularities is much more random.

Analysis of the value of selected 2D roughness parameters showed that for almost every case studied, the differences in values do not differ significantly. Only in the two analyzed cases, the critical value of the test was exceeded.

Similar results were obtained for all mother wavelets used in the analysis.

\section{REFERENCES}

[1] Jiang X., Blunt L. "Third generation wavelet for the extraction of morphological features from micro and nano scalar surface". Wear. 257 (2014): 1235-1240.

[2] Abdul-Rahman H.S., Jiang X., Scott P. "Freeform surface filtering using the lifting wavelet transform". Precision Engineering. 37 (2013): 187-202.

[3] Chen M., Pang Q., Wang J., Cheng K. "Analysis of 3D microtopography in machined KDP crystal surfaces based on fractal and wavelet methods". International Journal of Machine Tools and Manufacture. 48 (2008): 905-913.

[4] Zawada-Tomkiewicz A. "Estimation of surface roughness parameter based on machined surface image". Metrology and Measurement System. 17, 3 (2010): 493-504.

[5] Dutta S., Pal S.K., Sen R. "Progressive tool flank wear monitoring by applying discrete wavelet transform on turned surface images". Measurement. 77 (2016): 388-401.

[6] Zahouani H., Mezghani S., Vargiolu R., Dursapt M. "Identification of manufacturing signature by 2D wavelet decomposition". Wear. 264 (2008): 480-485.

[7] Josso B., Burton D.R., Lalor M.J. "Frequency normalized wavelet transform for surface roughness analysis and characterization". Wear. 252 (2012): 491-500.

[8] Makieła W., Gogolewski D. „Metoda rozdzielania składowych nierówności powierzchni za pomocą dwuwymiarowej transformaty falkowej". Mechanik. 11 (2016): 1716-1717, http://dx.doi.org/10.17814/mechanik.2016.11.506.

[9] Adamczak S., Świderski J., Dobrowolski T. „Analiza wpływu gęstości próbkowania poziomego na parametry chropowatości". Mechanik. 4 (2017): 332-334. 